\title{
O impacto das relações familiares no comportamento suicida
}

\author{
The impact of family relationships in the suicidal behavior \\ El impacto de las relaciones familiares em la conducta suicida
}

Recebido: 25/01/2021 | Revisado: 31/01/2021 | Aceito: 01/02/2021 | Publicado: 09/02/2021

\author{
Daniel Augusto da Silva \\ ORCID: https://orcid.org/0000-0002-2716-6700 \\ Universidade Federal de São Paulo, Brasil \\ E-mail: daniel.augusto@unifesp.br \\ João Fernando Marcolan \\ ORCID: https://orcid.org/0000-0001-8881-7311 \\ Universidade Federal de São Paulo, Brasil \\ E-mail: jfmarcolan@uol.com.br
}

\begin{abstract}
Resumo
Objetivo: Analisar o impacto das relações familiares no comportamento suicida. Metodologia: Pesquisa exploratória, descritiva, abordagem qualitativa, realizada de dezembro de 2017 a novembro de 2019 em Unidade de Pronto Atendimento de Assis/SP. Entrevistas realizadas com pessoas com tentativa de suicídio. Empregou-se referencial metodológico de Análise de Conteúdo. Projeto de pesquisa aprovado pelo Comitê de Ética em Pesquisa. Resultados: Entrevistados 113 participantes de total de 309 ocorrências de tentativa de suicídio identificadas no período. A maioria era do sexo feminino $86(76,1 \%)$, entre 18 e 30 anos $57(50,4 \%)$, heterossexuais $103(91,2 \%)$, cor de pele autodeclarada branca $62(54,9 \%)$, solteiros $49(43,4 \%)$, com ensino médio completo $41(43,2 \%)$. sem patologia física $70(61,9 \%)$, com transtorno mental 70 (61,9\%), sem uso de drogas 74 (65,5\%). Como fator de proteção, as relações familiares e o modelo familiar são caracterizados por apego familiar, com sentimentos de amor e respeito, e com apoio efetivo da família. Na outra ponta, como fator de risco as relações familiares negativas eclodem em brigas, violência familiar, sensação de não pertencimento e traição. Considerações finais: Família tem potencial de gerar impacto positivo quando apresenta apoio e apego sentimental entre seus membros, porém relações familiares desajustadas perfazem impacto negativo e se torna fator de risco para comportamento suicida.
\end{abstract}

Palavras-chave: Tentativa de suicídio; Família; Relações familiares; Fatores de risco; Fatores de proteção.

\begin{abstract}
Objective: To analyze the impact of family relationships on suicidal behavior. Methodology: Exploratory, descriptive research, qualitative approach, carried out from December 2017 to November 2019 in the Emergency Care Unit of Assis / SP. Interviews conducted with people attempting suicide. Content Analysis methodological framework was used. Research project approved by the Research Ethics Committee. Results: Interviewed 113 participants out of a total of 309 occurrences of attempted suicide identified in the period. The majority were female $86(76.1 \%)$, between 18 and 30 years old $57(50.4 \%)$, heterosexual 103 (91.2\%), self-declared white skin color 62 (54.9\%), single 49 (43.4\%), high school completed $41(43,2 \%)$. without physical pathology $70(61.9 \%)$, with mental disorder $70(61.9 \%)$, without drug use $74(65.5 \%)$. As a protective factor, family relationships and the family model are characterized by family attachment, with feelings of love and respect, and with effective support from the family. At the other end, as a risk factor, negative family relationships erupt in fights, family violence, a sense of non-belonging and betrayal. Final considerations: The family has the potential to generate a positive impact when it presents support and sentimental attachment among its members, but maladjusted family relationships have a negative impact and become a risk factor for suicidal behavior. Keywords: Suicide attempted; Family; Family relations; Risk factors; Protective factors.
\end{abstract}

\section{Resumen}

Objetivo: Analizar el impacto de las relaciones familiares en la conducta suicida. Metodología: Investigación exploratoria, descriptiva, abordaje cualitativo, realizada de diciembre de 2017 a noviembre de 2019 en la Unidad de Atención de Emergencias de Assis / SP. Entrevistas realizadas con personas que intentaron suicidarse. Se utilizó el marco metodológico de Análisis de Contenido. Proyecto de investigación aprobado por el Comité de Ética en Investigación. Resultados: Se entrevistó a 113 participantes de un total de 309 casos de intentos de suicidio identificados en el período. La mayoría eran mujeres 86 (76,1\%), entre 18 y 30 años 57 (50,4\%), heterosexuales 103 (91,2\%), autodeclarado color de piel blanca $62(54,9 \%)$, solteros $49(43,4 \%)$, con educación media completa $41(43,2 \%)$. sin patología física $70(61,9 \%)$, con trastorno mental $70(61,9 \%)$, sin consumo de drogas $74(65,5 \%)$. Como factor protector, las relaciones familiares y el modelo familiar se caracterizan por el apego familiar, con sentimientos de amor y respeto, y con un apoyo efectivo de la familia. En el otro extremo, como factor de riesgo, las relaciones familiares negativas 
estallan en peleas, violencia familiar, sentido de no pertenencia y traición. Consideraciones finales: La familia tiene el potencial de generar un impacto positivo cuando presenta apoyo y apego sentimental entre sus miembros, pero las relaciones familiares inadaptadas tienen un impacto negativo y se convierten en un factor de riesgo de conducta suicida.

Palabras clave: Intento de suicidio; Familia; Relaciones familiares; Factores de riesgo; Factores protectores.

\section{Introdução}

O comportamento suicida compreende a ideação suicida, a tentativa de suicídio e o suicídio propriamente dito, com ênfase ao constante aumento de mortes por suicídio que se mostra preocupante, e para as tentativas de suicídio que são ainda de maior prevalência na população geral (World Health Organization, 2019).

No Brasil, no período de 20 anos (1996 a 2016), houve o registro de 183.484 mortes por suicídio, um aumento de 69,6\% neste período. A taxa de mortalidade por suicídio em 2018 foi de 6,1 por 100.000 habitantes, com o registro de 12.733 mortes por suicídio (Silva \& Marcolan, 2020).

O impacto do suicídio sobre as famílias, amigos e comunidades é devastador e de longo alcance (World Health Organization, 2019), contudo, esse estudo propõe a reflexão sobre o impacto que a família pode gerar no comportamento suicida.

Sabe-se que no comportamento suicida há interferência das relações com familiares, com amigos e com outras pessoas com as quais haja relacionamento afetivo importante, de forma que o bom vínculo familiar assume papel de proteção ao comportamento suicida, enquanto que vínculos familiares conflituosos e dinâmica familiar conturbada são potenciais fatores de risco (World Health Organization, 2014; Oliveira, Melo, Aoyama, \& Lima, 2019; Cassorla, 1992).

A família, compreendidas as alterações estruturais e funcionais ocorridas nos últimos anos, mantém a característica de ser a principal base de segurança e bem-estar de seus membros, de forma que pode ser definida como um grupo social especial, no qual a intimidade, a afetividade e a intergeracionalidade sustentam os vínculos (Zappe \& Dapper, 2017).

Como relações familiares, compreende-se a interação entre seus membros nas diversas situações. Relações familiares positivas tem o objetivo constante de alcançar a homeostase familiar, e, ao ser atingida, caracteriza essas relações como coesas, estáveis e seguras. Entretanto, quando essas relações são conflitantes e distantes, influenciam a dinâmica familiar de modo negativo (Takahara, Furino, Marques, Zerbetto, \& Furino, 2017).

Nesta perspectiva, este estudo tem por objetivo analisar o impacto das relações familiares no comportamento suicida.

\section{Metodologia}

Trata-se de pesquisa exploratória, descritiva, com abordagem qualitativa, norteada pela ferramenta Consolidated Criteria for Reporting Qualitative Research - COREQ (Tong, Sainsbury, \& Craig, 2007) da rede Equator, realizada no período de dezembro de 2017 a novembro de 2019, na Unidade de Pronto Atendimento (UPA), componente da Rede de Atenção às Urgências no âmbito do Sistema Único de Saúde de Assis/SP. As UPAs 24h integram a Rede de Atenção às Urgências no âmbito do Sistema Único de Saúde e realizam atendimentos de urgência e emergência psiquiátrica, incluindo as tentativas de suicídio.

Os critérios de inclusão foram: pessoas atendidas no serviço de pronto atendimento, no período de coleta de dados, em decorrência de tentativa de suicídio e com idade igual ou superior a 14 anos. Pacientes com comprometimento cognitivo que impossibilitasse a participação na entrevista para coleta de dados foram excluídos do estudo. Consideramos comprometimento cognitivo a ocorrência de sonolência excessiva por efeito medicamentoso ou devido a quadro psíquico. A avaliação prévia foi realizada pelo pesquisador que realizou a entrevista.

Durante o período do estudo foram identificadas 309 tentativas de suicídio no referido município. Dessas 309 ocorrências, foi possível entrevistar 113 pessoas que tentaram suicídio e que se conseguiu abordar pessoalmente no momento da alta da UPA 24h. Não houve recusas aos convites de participação nem tentativas rigorosas para recrutar participantes. Não houve exclusão de participantes, todos atenderam aos critérios estabelecidos. 
A coleta de dados foi realizada por um dos pesquisadores, ambos com experiência sobre comportamento suicida, por meio de um formulário contendo variáveis sociodemográficas (sexo, idade, orientação sexual, cor da pele, escolaridade, orientação sexual e situação conjugal) e clínicas (autorrelato sobre presença de doenças físicas e transtorno mental e uso de substâncias psicoativas - lícitas e ilícitas). Ademais, para a entrevista qualitativa semiestruturada foi utilizado um roteiro, elaborado pelos pesquisadores, composto por múltiplas questões, e dentre elas, as que abordavam as relações familiares, como histórico de comportamento suicida em familiares, fatores de proteção e risco ao comportamento suicida devido as relações familiares. As entrevistas duraram, em média, 60 minutos e ocorreram em ambiente privativo, na própria unidade de saúde, de modo que os participantes pudessem responder as questões sem interferências e garantida a privacidade das informações. Todas as entrevistas foram realizadas com gravador de voz integralmente transcritas.

Para processamento e análise dos dados, empregou-se o referencial metodológico de Análise de Conteúdo temático. Neste método de análise, a pré-análise consiste na organização das entrevistas e leituras dos conteúdos em número suficiente para propiciar a extração das ideias centrais e seus significados. As entrevistas são integralmente transcritas (Bardin, 2011).

$\mathrm{Na}$ exploração do material foram feitas operações de codificação, categorização, decomposição ou enumeração. Por conveniência dos pesquisadores, não foi realizada a enumeração, ou seja, a frequência de aparição de certos elementos da mensagem. Para a construção das unidades de significação, que se alinharam ao objetivo desta pesquisa, as falas foram recortadas e categorizadas por temas (Bardin, 2011).

As normas que regulamentam a ética em pesquisa com seres humanos, dispostas na Resolução no 466/2012 do Conselho Nacional de Saúde e os princípios éticos da Declaração de Helsinque foram respeitados. O projeto de pesquisa foi submetido e aprovado pelo Comitê de Ética em Pesquisa da Universidade Federal de São Paulo, com Parecer n. ${ }^{\circ}$ 2.314.347, de 4 de outubro de 2017. Após a abordagem, identificação do possível participante, explicações sobre a pesquisa, seus objetivos, formas de participação e consentimento na participação, foi assinado o Termo de Consentimento Livre e Esclarecido. Para os participantes menores de 18 anos foi obtido o seu consentimento e a autorização por escrita do responsável legal no Termo de Assentimento Livre e Esclarecido.

\section{Resultados}

Foram entrevistadas 113 pessoas que tentaram o suicídio, num total de 309 ocorrências de tentativa de suicídio identificadas no município, no período de dezembro de 2017 a novembro de 2019. Em relação a caracterização sociodemográfica dos participantes, a maioria era do sexo feminino ( $\mathrm{n}=86 ; 76,1 \%)$, na faixa etária entre 18 e 30 anos $(\mathrm{n}=57 ; 50,4 \%)$, heterossexuais $(\mathrm{n}=103 ; 91,2 \%)$, cor de pele autodeclarada como branca $(\mathrm{n}=62 ; 54,9 \%)$, solteiros $(\mathrm{n}=49 ; 43,4 \%)$ e com ensino médio completo $(n=41 ; 43,2 \%)$. No que se refere às variáveis clínicas, em autorrelato a maioria não apresentava diagnóstico prévio de patologia física $(n=70 ; 61,9 \%)$, tinham diagnóstico de transtorno mental $(n=70 ; 61,9 \%)$, e referiu não utilizar substâncias psicoativas lícitas

ou ilícitas $(\mathrm{n}=74 ; 65,5 \%)$. Os transtornos mentais mais comuns foram ansiedade e depressão. Quanto ao método, a autointoxicação exógena foi o método mais empregado na tentativa de suicídio ( $\mathrm{n}=84 ; 74,3 \%)$.

A análise das entrevistas permitiu agrupar os dados em duas categorias: (1) As relações familiares como fator de proteção ao comportamento suicida, e (2) As relações familiares como fator de risco ao comportamento suicida, apresentadas a seguir:

\subsection{As relações familiares como fator de proteção ao comportamento suicida}

$\mathrm{Na}$ investigação sobre os fatores de proteção ao comportamento suicida, com a pergunta: "O que te protege para não tentar o suicídio novamente?", o apego familiar, com sentimentos de amor e respeito foi frequentemente apontado, bem como o apoio efetivo da família, quando se fazia presente. 
As relações familiares com o apego sentimental entre seus membros foi um fator afirmado como protetor a reincidência da tentativa de suicídio. As falas estão dispostas a seguir.

Meu filho e minha mãe, que eu hoje penso muito (E9).

A minha irmã está grávida da minha primeira sobrinha, e tem a minha avó que sofreu com câncer há um ano e nove meses e está com câncer de novo, e moro com ela desde que nasci (E10).

Minha família. Agora olho para eles e penso que não compensa esse negócio não (E14).

Minha filha e minha esposa (E20).

O que mais penso é nos meus filhos (E25).

Demorei um ano para arranjar outra pessoa que foi ele. Ele tem o jeito dele, mas ele é uma pessoa muito companheira. Ele é um apoio para mim (E43).

A presença dos meus filhos aqui. Nem que eles briguem, porque não suporto mais morar sozinha (E53).

Minha irmã. Ela se importa. E porque ela já perdeu três filhos. Se ela me perdesse, seria uma grande decepção para ela, então isso meio que me prende (E65).

Foi possível observar que o relacionamento entre os membros da família como apoio às pessoas, é positivo na prevenção do comportamento suicida, conforme apontado pelos entrevistados. Na sequência estão apresentadas algumas falas a este respeito.

Sempre ligo para alguém antes, daí perco a coragem (E16).

O dia que minha irmã veio e conversou comigo, comecei a chorar... é difícil, não tem explicação (E17).

Agora meu filho está em casa. Ele me protege. Agora ele está em casa e estou feliz (E34)

Penso numa internação, acompanhamento psicológico, psiquiátrico, e o apoio da família, mas isso é difícil (E77).

Final de semana ia fazer isso, aí o meu namorado me buscou e impediu. Aí ele me levou na casa dele (E103).

\subsection{As relações familiares como fator de risco ao comportamento suicida}

Nesta categoria foram reunidos os trechos das entrevistas que representam que a vivência de estressores no ambiente familiar pode atuar como fator de risco para o comportamento suicida. A pergunta que originou essa categoria foi: "O que te influencia a desenvolver o comportamento suicida?”.

Nas falas dos participantes, as brigas familiares dificultavam o convívio. Algumas vezes as brigas foram com membros específicos da família, e, em outras vezes todo o ambiente familiar era desarmonioso, conforme demonstram as afirmações a seguir.

É... A gente tem bastante desavenças, bastante brigas. No geral (E25).

A gente briga demais (E28).

Muita briga com a mãe e com o marido, que são as causas para o suicídio (E38).

Uma bosta. Com meu pai é de boa. Minha mãe, não converso com ela por causa de briga (E45).

Não é muito boa. Tem muita briga. Toda família tem, mas a base certa da minha casa era minha avó, que faleceu, aí... Desistiram (E52).

Brigo muito com minha mãe (E84). 
As violências do tipo física e psicológica foram citadas como situações enraizadas no ambiente familiar, de modo que o conflito dominava as relações familiares.

Moro com meu marido. A gente briga bastante, ele gosta de me bater. Mas quando ele sai, fico sozinha e me dá desespero (E1).

Meu esposo bebe, me maltrata... Cuido da minha cunhada, minha cunhada tem problema, me xinga, me maltrata muito. É... Meu filho também é muito bravo. É casado. Está morando dentro de casa (E21).

Teve violência familiar. Meu padrasto me batia. Meu irmão fazia as coisas e eu apanhava. Foi quando comecei a entrar em depressão, por causa dele. Ele brigava com minha mãe e me culpava (E62).

O desarranjo familiar, com afastamento dos membros, foi apontado como situação que gera sensação de não pertencimento, e, consequentemente, sentimentos negativos. A seguir algumas falas são apresentadas.

A família não ajuda em nada. Não ajuda em apoio moral e nem financeiro. Atrapalha. Me sinto muito sozinha. Falo da minha mãe, das minhas irmãs (E1).

Não tenho família nenhuma, moro sozinha (E3).

... o meu problema é mais familiar, sinto muita indiferença de certas coisas, até que tomo os remédios e tudo (E17).

Me afasto de todos... Moro com meu esposo. Meus filhos não, moram com o pai deles, meu primeiro marido (E33).

... sinto que ninguém gosta de mim. Filho usuário de drogas há 14 anos (E53).

O fato de ter sido traído (a) foi experiência marcante e decepcionante, causadora de intenso sofrimento. As experiências narradas estão a seguir.

Na verdade, sou solteira, mas tenho um relacionamento, atualmente estou com uma pessoa, mas essa pessoa já foi namorado meu no passado. A gente não deu certo no começo, depois voltamos e deu tudo errado, ele me traiu com minha filha. Minha filha com outro marido (E12).

É que meus pais foi que desencadeou tudo. ... Sou muito apegada a meu pai... meu pai foi aquele cara que sempre traiu minha mãe, e minha mãe naquele relacionamento abusivo desde sempre (E23).

... marido me traiu com a empregada e casou com ela (E53).

\section{Discussão}

Esse estudo buscou avaliar o impacto das relações familiares no comportamento suicida. Os achados dessa investigação apontaram que a família pode atuar como papel protetor ou de risco para a tentativa de suicídio.

A construção do indivíduo recebe significativa influência por parte da sociedade. Fatores sociais como a família, a escola, os grupos de que participa, os amigos e a sociedade são decisivos na produção do episódio suicida, exerce influência para a ocorrência ou não do suicídio na vida do indivíduo (Rodríguez, 2006; Andrés, 2005).

Revisão de literatura aponta que a família e a satisfação no relacionamento com os pais foram os maiores fatores de proteção para tentativa de suicídio em adolescentes. E por mais que exista discussão sobre a pluralização do conceito de família na sociedade atual, adolescentes que integravam famílias nucleares apresentaram menor incidência de tentativa de suicídio 
quando comparado a outros adolescentes de famílias com pais divorciados ou famílias nas quais um membro já havia falecido, a ressaltar que a formação familiar é importante fator protetivo, e não somente a dinâmica familiar e qualidade do vínculo, que é defendido com maior afinco (Braga \& Dell’Aglio, 2013).

Há situações e comportamentos que funcionam como proteção ao comportamento suicida. Para a maioria dos participantes deste estudo, essa proteção é relacionada as relações interpessoais, sobretudo as relações familiares. Entendemos dessa forma, que os mais presentes fatores de proteção estavam relacionados ao modelo familiar, que incluem o desejo de bemestar dos membros da família, as relações saudáveis, a interrupção de brigas e desentendimentos, e o amor e o apego a membros da família.

É no ambiente familiar que se concebe relações profundas e duradouras, que integra comunicação positiva, regras coerentes e flexíveis, liderança democrática, autoestima e preservação da individualidade de seus membros, de forma que, a partir dessas relações, ocorre o desenvolvimento saudável dos seus membros e o aprendizado para conviver em grupos, com vistas a interação social e manutenção da integridade física e psicológica. É nesse contexto que a família é classificada como um sistema de suporte (Souza \& Baptista, 2008).

A importância das relações positivas nesse contexto familiar é endossada quando a inabilidade para se relacionar com a família está presente na história de vida e modula comportamento de pessoas que desenvolvem o comportamento suicida. O envolvimento da família é uma das estratégias de intervenção como sistema de apoio social para pessoas com comportamento suicida (World Health Organization, 2000).

Esses laços familiares, como constituintes de uma rede de apoio social, assumem posição de fator de proteção ao ser humano, sobretudo quando este se encontra em situações adversas, de forma que esse apoio apresenta potencial para diminuir o impacto psicológico gerado por essas situações, pois concede apoio instrumental, por meio de apoio financeiro, auxilio nas atividades a serem executadas e assistência na clarificação do pensamento mediante fornecimento de informações, e apoio emocional com recebimento de benquerença, apreço, empatia, fraternidade, atenção e presteza no cuidado (Schneider \& Ramires, 2007; Anestis, Harrop, Green, \& Anestis, 2017).

Em outras palavras, o apoio familiar concerne à integração social, que se refere a assiduidade e repetição das relações com outras pessoas; o apoio recebido, que retrata o apoio palpável e efetivo recebido; e o apoio percebido, que analisa o atendimento das necessidades na perspectiva do recebedor, do senso de pertencimento e de certeza de que receberá apoio quando for necessário (Paúl, 2005; Borges, García del Castillo, Marzo, \& García del Castillo-López, 2016).

Assim, é notória a importância e necessidade de ampliação do suporte social por meio da criação ou fortalecimento ou ambos de redes de apoio social às pessoas, pois é um importante meio com competência para identificação e atenuação de situações adversas, negativas e penosas, pela compreensão e amparo frente a oportunidade de confidenciar sentimentos e emoções oriundos de dor e sofrimento, que produzem impulso positivo ao descarregar e confidenciar o sofrimento vivido, que, por sua vez, eclodem na escolha pela continuidade da vida (Andrade, et al., 2019).

Em contrapartida, a necessidade de senso de pertencimento ao grupo social a que se escolhe pode tornar-se um problema quando este não se enxerga inserido no contexto desejado, situação essa que, por vezes, torna-se uma sina ao ponto de autodesvalorização e supervalorização do outro. Inicia-se o processo de desalojamento do ser, no qual a expectativa não correspondida gera frustração, fracasso e sentimento de inutilidade (Fukumitsu, 2018).

Neste contexto, a desesperança, fruto do pensamento de incompetência pessoal para atingir os alvos utópicos de sucesso e felicidade auto estabelecidos, com a inexistência do sofrimento, torna-se enraizada, de forma que o pensamento de desacreditação em si e no outro é intenso, ao ponto de não conseguir pensar em outro conteúdo, se não o desapontamento da não conquista projetada. Identifica-se assim a rigidez de pensamento, uma característica presente no comportamento suicida (Fukumitsu, 2018; World Health Organization, 2014). 
Contudo, se por um lado a família é entendida como fator protetivo ao comportamento suicida, por outro, quando as relações familiares são desajustadas e não saudáveis, ela assume posição de fator de risco. A falta de apoio familiar, com precariedade das relações sociais torna o ambiente familiar desagradável e intolerável (Silva, et al., 2015).

Importante associação com fatores de risco para suicídio são as comunidades onde as pessoas vivem, incluídas a diversidade cultural, religiosa, legal e histórica, que proporcionam diferentes formas de entendimento e realidade social acerca do suicídio. As relações sociais vivenciadas nas comunidades também podem gerar impacto sobre comportamentos suicidas, compreendendo relações familiares, com amigos, e com outras pessoas com significado afetivo importante (World Health Organization, 2014).

Quanto à escassez das relações, é importante ressaltar a deficiência atual nas relações familiares, a contribuir mais ainda para o isolamento e desamparo individual, por conta do envolvimento nas conquistas individuais, e a isto, a busca por soluções frente ao vazio existencial inclui a dimensão dos vícios que causem prazer, sendo abuso do álcool, drogas, jogos, internet, atividade física, comida, entre outras, contudo, esses comportamentos resultam em aumento do sofrimento psíquico (Silva, 2016).

$\mathrm{Na}$ análise sobre as relações entre os membros da família e a estrutura familiar, constata-se a associação, seja ela positiva ou negativa, em relação ao comportamento suicida. As relações negativas, com baixa coesão familiar e vínculos frágeis, culminam em vulnerabilidade ao suporte social, que, quando escasso, pode exacerbar comportamentos de risco (Veras, Silva, \& Katz, 2017).

As dificuldades de relacionamento e de comunicação, a ausência de afeto e a falta de apoio são características presentes e que descrevem os relacionamentos familiares desajustados e conflitantes. A experiência da exposição a ambiente de baixa coesão, desestruturação familiar, incapacidade de desenvolvimento da promoção de apoio e sustentação emocional, promove o comportamento suicida em adolescentes, jovens e idosos, que passam a vivenciar o deslocamento e sensação de não pertencimento ao contexto familiar (Fernandes-Eloi \& Lourenço, 2019; Veras, Silva, \& Katz, 2017).

Essa sensação de não pertencimento pode ser percebida por adolescentes, inclusive, na falta de repreensão e imposição de limites frente a comportamentos de risco como a embriaguez e o absenteísmo escolar sem permissão, pois sentem e percebem a indiferença, abandono, descaso, insegurança e dificuldade de comunicação nas relações familiares (Baggio, Palazzo \& Aerts, 2009).

Destaca-se que a harmonia e intimidade entre pais e filhos, com comunicação aberta e regularmente presente, e com o desenvolvimento da formação educativa, incluindo ações de proteção, determinação de obrigações e controle do comportamento assumem papel preventivo ao comportamento suicida, pois resultam em crescimento e amadurecimento saudável e responsável. Por outro lado, viver em um ambiente de negligência de cuidado pelos pais, com permissividade de caráter excessivo gera agravos no crescimento e desenvolvimento pessoais (Magnani \& Staudt, 2018; Moreno-Carmona, Andrade-Palos, \& BetancourtOcampo, 2018; Iarrocheski \& Perrelli, 2020).

Os conflitos familiares, que envolvem briga, violência física e verbal, decepção, mágoas, ressentimento e interrupção da comunicação são situações de risco ao comportamento suicida, e frequentemente encontrados como experiência de pessoas que tentaram o suicídio (Marquetti \& Milek, 2014; Nascimento, 2020; Iarrocheski \& Perrelli, 2020; Czapski, Barbosa \& Monteiro, 2020; Almeida, Silva, \& Caixeta, 2020; Silva, Vecchia, Ramos, \& Costa, 2020).

Essa violência vivenciada em ambiente familiar gera insegurança, medo e angústia, e perde-se o pertencimento pois deixam de se enxergar em um ambiente que supostamente seria um espaço de proteção, respeito e afeto (Silva, Lima, Barboza, Ribeiro, \& Nepomuceno, 2020).

Ainda, deve-se atentar ao comportamento dos filhos em relação aos idosos. Mesmo que na intenção de ajudar e cuidar, as recorrentes tentativas de controlar ações e comportamentos dos idosos podem gerar sensação de não pertencimento, perda de 
autonomia e de identidade. Esses são frequentes relatos associados aos conflitos familiares e consequente desenvolvimento do comportamento suicida nos idosos (Costa \& Souza, 2017).

Os conflitos familiares ainda podem sofrer interferência relacionada ao uso de drogas, um dos vinte fatores de risco relacionado à saúde mais frequentes, e com crescente número de pessoas envolvidas (Silva, Pereira Junior, Gomes, \& Cardoso). Em uma perspectiva de causa e efeito, a família pode assumir papel de proteção ou de risco ao uso de drogas (Zappe \& Dapper, 2017; Schenker \& Minayo, 2003; Sena, Santos, Subrinho, \& Carvalho, 2018). Como risco, famílias disfuncionais são caracterizadas por déficit na comunicação, na definição de regras e limites e no afeto (Rosa \& Antoniassi Junior, 2017).

Para os efeitos prejudiciais que as drogas causam nas famílias, estima-se que 9\% da população brasileira convivam com essa situação (Belotti, Fraga, \& Belotti, 2017), e que a família tende a se afastar do usuário, pois o fato do uso das drogas é causa sofrimentos de várias ordens (Borges, OMoré, Krenkel, \& Schneider, 2017).

Ainda, a violência física no ambiente familiar é uma situação de preocupação. Ocorre de maneira simétrica entre os sexos, mas com efeito maior para mulheres. A dificuldade em manter laços parentais em ambientes de violência é uma das consequências que deturpa o significado de família (Franco, Magalhães, \& Féres-Carneiro, 2018; Madalena, Carvalho, \& Falcke, 2018).

Por conseguinte, ressaltamos a necessidade da abordagem familiar com construção e desenvolvimento da capacidade de entendimento, reação e enfrentamento das situações vividas, pontos chaves ao estabelecimento de relações e vínculo familiar funcional. Pensar e desejar a inexistência de problemas pessoais ou coletivos, ou existência exclusiva de situações agradáveis, ou ambas, seria utopia (Bastos, 2009; Krüger \& Werlang, 2010).

Este estudo se limita pelo recorte geográfico, de modo que foi realizado com pessoas em atendimento por tentativa de suicídio em uma determinada instituição de saúde, em município do estado de São Paulo, e descreve uma situação local de comportamento e experiências relacionadas à família, fato que impossibilita a generalização dos resultados apresentados. Contudo, deve-se considerar a importância do tema e das discussões a este respeito, tendo em vista o impacto produzido no comportamento suicida.

Aos profissionais de saúde, os achados deste estudo auxiliam a compreensão multifatorial do fenômeno do suicídio, e expõe possibilidades para a intervenção nas relações familiares, ampliando-as quando em fator de proteção ou reabilitação enquanto fator de risco.

\section{Considerações Finais}

A família tem o potencial de gerar impacto positivo, quando apresenta apoio e apego sentimental entre seus membros, e, desta forma, prevenir o comportamento suicida. Por outro lado, relações familiares desajustadas promovem impacto neg ativo, quando se vivencia brigas, violência, isolamento e traição, e se torna fator de risco ao desenvolvimento do comportamento suicida. Desta forma, entende-se que a terapia familiar assume importante e necessária ação de prevenção ao comportamento suicida. Futuras investigações devem ser realizadas para ampliar o conhecimento sobre essa temática, bem como avaliar intervenções familiares efetivas para a promoção da saúde mental de indivíduos com risco para o comportamento suicida.

\section{Financiamento}

Coordenação de Aperfeiçoamento de Pessoal de Nível Superior (CAPES) - Processo n. ${ }^{\circ}$ 88882.430471/2019-01. 


\section{Referências}

Almeida, M. N., Silva, N. S., \& Caixeta, C. C. (2020). Importância do atendimento qualificado a indígenas com tentativa de suicidio: relato de experiência. Revista do NUFEN, 12(3), 217-231. https://dx.doi.org/10.26823/RevistadoNUFEN.vol12.n'03rex.36

Andrade, I. C. S., Gomes, N. P., Correia, C. M., Lírio, J. G., Virgens, I. R., Gomes, N. P., \& Monteiro, D. S. (2019). Suporte social de familiares e amigos: discurso de pessoas com comportamento suicida. Cogitare enfermagem, 24, e64230. 10.5380/ce.v24i0.64230

Andrés, A. R. (2005). Income inequality, unemployment, and suicide: a panel data analysis of 15 European countries. Applied Economics, 37, 439-451. $10.1080 / 0003684042000295304$

Anestis, J. C., Harrop, T. M., Green, B. A., \& Anestis, M. D. (2017). Psychopathic personality traits as protective factors against the development of posttraumatic stress disorder symptoms in a sample of national guard combat veterans. Journal of Psychopathology and Behavioral Assessment, 39, 1-10. $10.1007 / \mathrm{s} 10862-017-9588-8$

Baggio, L., Palazzo, L. S., \& Aerts, D. R. G. C. (2009). Planejamento suicida entre adolescentes escolares: prevalência e fatores associados. Cadernos de Saúde Pública, 25(1), 142-150.

Bardin, L. (2011). Análise de conteúdo. (7a ed.) Edições 70.

Bastos, R. L. (2009). Suicídios, psicologia e vínculos: uma leitura psicossocial. Psicologia USP, 20, 67-92. 10.1590/S0103-65642009000100005

Belotti, M., Fraga, H. L., \& Belotti, L. (2017). Família e atenção psicossocial: o cuidado à pessoa que faz uso abusivo de álcool e outras drogas. Cadernos Brasileiros de Terapia Ocupacional,25, 617-625. 10.4322/2526-8910.ctoAR0988

Borges, C. D., OMoré, C. L. O. O., Krenkel, S. \& Schneider, D. R. (2017). Família, redes sociais e o uso de drogas: tensionamento entre o risco e a proteção. Pesquisas e Práticas Psicossociais, 12, e1396. http://seer.ufsj.edu.br/index.php/revista_ppp/article/view/2588

Borges, J. M., García del Castillo, J. A., Marzo, J. C., \& García del Castillo-López, A. (2016). Relações entre suporte social, autorregulação e consumo de outras substâncias em adultos portugueses. Actualidades en Psicología, 30, 67-75. 10.15517/ap.v30i121.24657

Braga, L. L., \& Dell’Aglio, D. D. (2013). Suicídio na adolescência: fatores de risco, depressão e gênero. Contextos Clínicos, 6, 2-14. 10.4013/ctc.2013.61.01

Cassorla, R. M. S. (1992). O que é suicídio. (4a ed.), Editora Brasiliense.

Costa, A. L. S., \& Souza, M. L. P. (2017). Narrativas de familiares sobre o suicídio de idosos em uma metrópole amazônica. Revista de Saúde Pública, 51, 121. $10.11606 / \mathrm{s} 1518-8787.2017051007059$

Czapski, A. R. S., Barbosa, H. C., \& Monteiro, M. D. S. (2018). Saúde mental vigilância, prevenção e atenção ao suicídio. Revista Extensão, 2(1), 49-54.

Fernandes-Eloi, J., \& Lourenço, J. R. C. (2019). Suicídio na Velhice - Um Estudo de Revisão Integrativa da Literatura. CES Psicologia, 12, 80-95. 10.21615/cesp.12.1.7

Franco, D. A., Magalhães, A. S., \& Féres-Carneiro, T. (2018). Violência doméstica e rompimento conjugal: repercussões do litígio na família. Pensando familias, 22, 154-171. Recuperado de http://pepsic.bvsalud.org/scielo.php?script=sci_arttext\&pid=S1679-494X2018000200011\&lng=pt\&tlng=pt.

Fukumitsu, K. O. (2018). Suicídio: do desalojamento do ser ao desertor de si mesmo. Revista USP, 119, 103-114. 10.11606/issn.2316-9036.v0i119p103-114

Iarrocheski, L. Z. \& Perrelli, M. T. (2020). Antes do fim da linha: suicídio na contemporaneidade. Cadernos Zygmunt Bauman, 10 (22), 2-16.

Krüger, L. L., \& Werlang, B. S. G. (2010). A dinâmica familiar no contexto da crise suicida. Psico-USF, 15, 59-70. 10.1590/S1413-82712010000100007

Madalena, M., Carvalho, L. F., \& Falcke, D. (2018). Violência Conjugal: O Poder Preditivo das Experiências na Família de Origem e das Características Patológicas da Personalidade. Trends in Psychology, 26(1), 75-91. 10.9788/tp2018.1-04pt

Magnani, R. M., \& Staudt, A. C. P. (2018). Estilos parentais e suicídio na adolescência: uma reflexão acerca dos fatores de proteção. Pensando Famílias, 22, 75-86. http://pepsic.bvsalud.org/pdf/penf/v22n1/v22n1a07.pdf

Marquetti, F. C. \& Milek, G. (2014). Percurso Suicida: observação e análise. Rev Ter Ocup Univ São Paulo, 25(1), 18-26. 10.11606/issn.2238-6149.v25i1p1826

Moreno-Carmona, N. D., Andrade-Palos, P., \& Betancourt-Ocampo, D. (2018). Fortalezas en adolescentes de Colombia y México que nunca han intentado suicidarse. Revista Latinoamericana de Ciencias Sociales, Niñez y Juventud, 16, 797-807. 10.11600/1692715x.16210

Nascimento, G. S. (2020). Possibilidades a prevenção do suicídio dos jovens. Revista Científica Multidisciplinar Brillant Mind, 1(1), 27-42.

Oliveira, F. B. S., Melo, K. C. F., Aoyama, E. A., \& Lima, R. N. (2019). Suicídio na velhice como um fenômeno cada vez mais crescente e preocupante. Revista Brasileira Interdisciplinar de Saúde, 1, 1-7. https://revista.rebis.com.br/index.php/rebis/article/view/252/91

Paúl, C. (2015). Envelhecimento activo e redes de suporte social. Sociologia: Revista da Faculdade de Letras da Universidade do Porto. 15, $275-287$. https://www.redalyc.org/pdf/4265/426540419011.pdf

Rodríguez, A. (2006). Inequality and suicide rates: A cross-country study. institute for advanced development studies. Development Research Working Paper Series, 13. http://www.inesad.edu.bo/pdf/wp13_2006.pdf 
Rosa, B. S., \& Antoniassi Junior, G. (2017). A constituição dos vínculos e estilos familiares quando os filhos fazem uso das drogas. Psicologia e Saúde em Debate, 3, 127-140. http://www.psicodebate.dpgpsifpm.com.br/index.php/periodico/article/view/94/78

Schenker, M., \& Minayo, M. C. S. (2003). A implicação da família no uso abusivo de drogas: uma revisão crítica. Ciência \& Saúde Coletiva, 8, 299-306. https://www.scielosp.org/article/csc/2003.v8n1/299-306/pt/

Schneider, A. C. N., \& Ramires, V. R. R. (2007). Vínculo parental e rede de apoio social: relação com a sintomatologia depressiva na adolescência. Aletheia, 26, 95-108. http://pepsic.bvsalud.org/pdf/aletheia/n26/n26a09.pdf

Sena, E. L. S., Santos, V. T. C., Subrinho, L. Q., \& Carvalho, P. A. L. (2018). Percepção da família de adolescentes sobre o cuidado no contexto do consumo de drogas. Revista Eletrônica de Enfermagem, 20, v20a20. doi; 10.5216/ree.v20.48274

Silva, D. A., \& Marcolan, J. F. (2020). Epidemiologia do suicídio no Brasil entre 1996 e 2016 e a política pública. Research, Society and Development, 9 , e79922080. 10.33448/rsd-v9i2.2080

Silva, D. A., Pereira Junior, R. J., Gomes, C. F. M., Cardoso, J. V. (2019). Envolvimento com álcool, tabaco e outras substâncias por estudantes universitários. Revista Cuidarte, 10(2), e641. 10.15649/cuidarte.v10i2.641

Silva, F. G., Lima, J. F., Barboza, M. A., Ribeiro, O. N. S. F., \& Nepomuceno, W. R. (2020). Aspectos socioeconômicos e risco de suicídio em adolescentes fluminenses. Brazilian Journal of Development, 6(11), 92263-92283. 10.34117/bjdv6n11-634

Silva, L. L. T., Vecchia, B. P., Ramos, T. M., \& Costa, T. A. F. (2020). Profissionais de enfermagem de um serviço de urgência e emergência frente ao suicídio na adolescência. Revista Eletrônica Acervo Saúde, 12(10), e4042. 10.25248/reas.e4042.2020

Silva, S. P. (2016). Suicídio: da cultura do consumo ao consumir da vida. São Leopoldo. (Dissertação de Mestrado em Teologia, Faculdades EST). http://dspace.est.edu.br:8000/xmlui/bitstream/handle/BR-SIFE/643/silva_sp_tmp452.pdf?sequence=1\&isAllowed=y

Silva, R. M., Mangas, R. M. N., Figueiredo, A. E. B., Vieira, L. J. E. S., Sousa, G. S., Cavalcanti, A. M. T. S., \& Apolinário, A. V. S. (2015). Influências dos problemas e conflitos familiares nas ideações e tentativas de suicídio de pessoas idosas. Ciência \& Saúde Coletiva, 20, 1703-1710. 10.1590/141381232015206.01952015

Souza, M. S., \& Baptista, M. N. (2008). Associações entre suporte familiar e saúde mental. Psicologia Argumento, 26, 207-215. https://periodicos.pucpr.br/index.php/psicologiaargumento/article/view/19753/19065

Takahara, A. H., Furino, V., Marques, A. C., Zerbetto, S., \& Furino, F. (2017). Relações familiares, álcool e outras drogas: uma revisão integrativa. Revista de APS - Atenção Primária À Saúde, 20(3), 434-443. 10.34019/1809-8363.2017.v20.15999

Tong, A., Sainsbury, P., \& Craig, J. (2007). Consolidated criteria for reporting qualitative research (COREQ): a 32-item checklist for interviews and focus groups. International Journal for Quality in Health Care, 19, 349-357. 10.1093/intqhe/mzm042

Veras, J. L. A., Silva, T. P. S., \& Katz, C. T. (2017). Funcionamento familiar e tentativa de suicídio entre adolescentes. Cadernos Brasileiros de Saúde Mental, 9, 70-82. https://periodicos.ufsc.br/index.php/cbsm/article/view/69090/41545

World Health Organization. (2014). Preventing suicide: a global imperative. Geneva, WHO.

World Health Organization. (2000). Prevenção do suicídio: um manual para profissionais da saúde em atenção primária, transtornos mentais e comportamentais. Genebra, WHO.

Zappe, J. G., \& Dapper, F. (2017). Drogadição na adolescência: família como fator de risco ou proteção. Revista de Psicologia da IMED, 9, 140-158. 10.18256/2175-5027.2017.v9i1.1616 